\title{
Measuring Affective Well-Being by the Combination of the Day Reconstruction Method and a Wearable Device: Case Study of an Aging and Depopulating Community in Japan
}

\author{
Junichirou Ishio ${ }^{1} \cdot$ Naoya Abe $^{2}$
}

Received: 24 November 2016/ Accepted: 15 February 2017/Published online: 23 February 2017

(C) Springer SBM Singapore Private Ltd. 2017

\begin{abstract}
Affective well-being indicates the changes in the predominance of positive or negative affects of people in response to their daily experiences. For measuring affective well-being, people are usually asked to indicate their affective states in several episodes that they experienced in a day. However, such conventional methods have been problematic in terms of their burdensomeness on participants and the validity of the rating. To overcome these problems, we attempted to introduce a new approach for measuring affective states, based on the combination of the day reconstruction method and the measurement of physiological stress levels by a wristband-type wearable device. As the indicator of physiological stress levels, we used heart rate variability calculated from the data recorded by the device. We examined the interpretability of the physiological stress level as a substitute for affective states by applying this combinational approach to an aging and depopulating village in Japan, because the well-being of the residents in such areas is a matter of public concern. As a result, we could depict the sources of affective well-being
\end{abstract}

Junichirou Ishio

ishio.j.aa@m.titech.ac.jp

Naoya Abe

nabe@ide.titech.ac.jp

1 Department of International Development Engineering (IDE), Graduate School of Science and Engineering, Tokyo Institute of Technology, I4-4, 2-12-1, Ookayama, Meguro City, Tokyo 152-8550, Japan

2 Department of Transdisciplinary Science and Engineering, School of Environment and Society, Tokyo Institute of Technology, I4-4, 2-12-1, Ookayama, Meguro City, Tokyo 152-8550, Japan and the physiological stressors in the village. We also found a reasonable, but weak, correlation between the scores of affective states and the indicator of physiological stress levels. We discussed the challenges that should be overcome for utilizing the physiological stress level as a substitute for affective state.

Keywords Affective well-being - Day reconstruction method - Stress $\cdot$ Wearable device $\cdot$ Aging and depopulation

\section{Introduction}

Observing people's affective states in various situations of their daily lives is one of the approaches for assessing their levels of well-being. The predominance of positive and negative affects in daily life can be regarded as a barometer of affective well-being [20]. By associating the situations with affective states, we can evaluate how each situation is affecting people's well-being. This study is a new attempt to utilize a wearable device for observing people's affective states, which could replace the Kahneman's approach eventually. We considered "stress" as an intermediator between daily life episodes and the affective states of people and tried to measure the stress level in a physiological way by introducing a wristband-type wearable device. This device can record the wearers' RRIs (R-to-R intervals of heart rates) easily in a noninvasive way, and the variability of RRIs (known as heart rate variability: HRV) is one of the indicators of physiological stress level $[22,45]$. We conducted a case study in an aging and depopulating community in Japan because the effects of aging and depopulation on people's daily life are seemingly getting more significant in Japan. 


\section{Objectives}

The objectives of this study were twofold. One was to assess people's affective well-being in an aging and depopulating community using the new method proposed by this study, which is a combination of the day reconstruction method (DRM) and the measurement of physiological stress levels by a wristband-type wearable device. The other was to examine how this approach could improve the conventional methods of affective well-being measurement by investigating the relationship between the affective states and the physiological stress levels of people and how well physiological stress levels interpret the people's affective states.

\section{Motivations and Challenges in Measuring Affective Well-Being}

Although the pursuit of well-being has been important for all of humanity, defining well-being is still problematic. Scholars have been proposing various constituents and determinants of well-being [9, 10, 13, 20, 21, 40]. In this article, we follow the classification of the five dimensions of well-being [12, 13, 25, 40]. They are (1) preference satisfaction; (2) objective lists; (3) eudemonic well-being; (4) cognitive well-being; and (5) affective well-being (Fig. 1).

Although measuring all these dimensions is important [40], objective well-being (OWB) has tended to be paid more attention than subjective well-being (SWB) because of its objectivity and data availability. However, as the limitation of OWB is becoming more serious, the interest in measuring SWB has increased among scholars and policymakers these days. For example, the Organization for Economic Cooperation and Development (OECD) and the government of the United Kingdom launched the "OECD Better Life Initiative" in 2011 and the "National Wellbeing Programme" in 2010, respectively. They are annually reporting citizens' SWB in addition to their OWB $[14,17]$. They believe that SWB has the potential to enable them to comprehend people's well-being in a more direct way [21].

In measuring SWB, scholars have generally focused on cognitive well-being, which is based on the global retrospective evaluation of life satisfaction or happiness [8, 10]. However, Kahneman and Krueger [21] pointed out that the measurement of cognitive well-being is not suited for measuring the actual well-being experienced or being experienced by the people. This is because there is sufficient evidence that suggest that the rating of a person's cognitive well-being is determined mainly by the personality of the person, the person's current moods, and limited number of recalled memories when they evaluate their cognitive well-being. Most of the experiences in their daily lives are tend to be disregarded in measuring cognitive well-being. Therefore, Kahneman and Krueger [21] advocated the importance of measuring affective well-being, which considers the affective states experienced or being experienced by the people, in addition to measuring cognitive well-being. By measuring affective well-being, we can understand the effects based on the situation that people experience in their daily lives.

There are two popular methods for measuring affective well-being: the Experience Sampling Method (ESM) and DRM. In ESM, people indicate their current affective states at several random points of time throughout a day [19], whereas in DRM, people indicate their affective states during the episodes that they experienced on the preceding day [20]. Both methods collect the details about the situations corresponding to the affective states of an individual.
Fig. 1 The classification of well-being (Sources: Dolan et al. [13], Stiglitz et al. [40], Kahneman and Krueger [21], Kahneman et al. [20], Dasgupta [9], Diener [10])

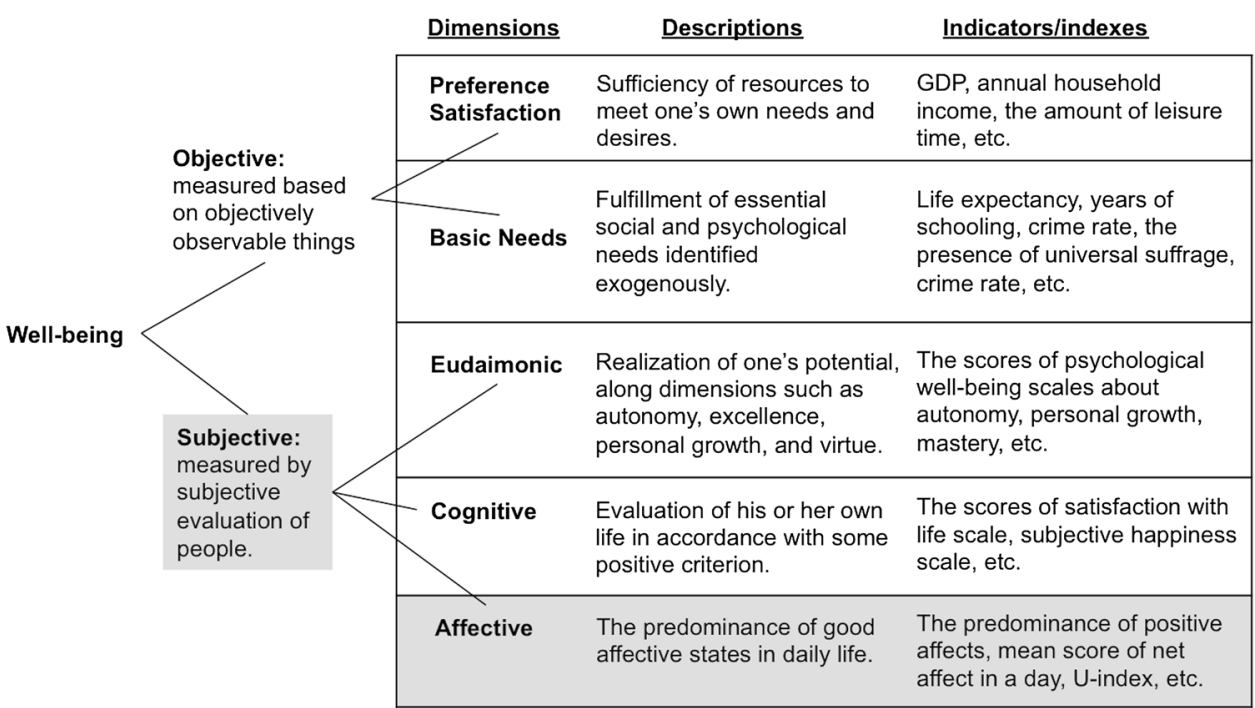


Commonly, the situations are illustrated by, "activity", "location", and the "people with whom" they interact, and the recalled situation is called "episode" in DRM [20].

However, the measurement of affective well-being has some challenges. Participation in ESM is burdensome for people because it sometimes interrupts their primary activities. Reducing the burden of ESM requirements was one of the reasons why Kahneman et al. [20] developed DRM; but Diener and Tay [11], however, were skeptical about the validity of DRM and recommended using ESM instead. For measuring affective well-being, more valid and less burdensome methods are required while ensuring the validity of the collected information. There have been attempts to realize such methods by introducing electronics. For example, Perrez et al. [30] introduced palmtop computers into ESM to support the participants' real-time self-report. Diener and Tay [11] suggested replacing palmtop computers with smartphones to possibly lessen the burden. The methods for measuring affective well-being have evolved along with the advancement in electronics. However, these studies still rely on self-report for measuring affective states. Although electronic devices enable participants to indicate the surrounding situations on time, the burdens and difficulties of having to stop their primary activities just to evaluate their affective states and indicate the appropriate descriptors for the situations one by one remain. Therefore, we attempt and examine the new method to objectively and automatically evaluate people's affective well-being through the introduction of a wearable device.

\section{Measuring Affective Well-Being by a Wearable Device}

While producing the palmtop computers and the smartphones, the advancement in the electronics, especially in the sensing technologies, has also been producing the devices, which have the potential to be utilized for the objective and automatic measurement of affective wellbeing. Wearable device is one of the fruits of the advancement. Some types of the wearable devices provide us the means to collect various types of physiological information, which may possibly be the expressions of the affective states. As an example, Seigneur [33] attempted to measure affective well-being, which was described as "real time happiness" and illustrated by some types of emotions such as "engagement" and "frustration", through monitoring electroencephalogram (EEG) by a wearable braincomputer interface.

In this research, we introduce a wristband-type wearable device, which mounts a photoplethysmography (PPG), enabling us to record the wearer's RRIs in a noninvasive way. Compared to the other types of wearable devices, this kind of wristband-type device seems to be less interruptive and more acceptable in the most of the situations that ordinal people experience in their daily lives. To mitigate the burden of indicating the affective states, we try to anticipate people's affective states based on their physiological stress levels calculated from the RRI data recorded by this wearable device.

We attempt to use an indicator of physiological stress level as a proxy variable of affective states because researchers show a significant negative correlation between physiological "stress" and well-being-mainly cognitive and affective well-being [6, 31, 42]. The indicator of physiological stress level is obtained by calculating the variability of RRIs-HRV. To authenticate this idea, we need to exposit the notions of physiological stress, HRV, and psychological stress, and their relationship with well-being.

\section{Physiological Stress and HRV}

Originally, "stress" has been used as a nontechnical word that means the hardship [24]; however, after a series of studies on physiological stress responses by Selye [34-36], "stress" has been investigated as a multifaceted notion mainly in the fields of physiology and psychology.

Selye [34-36] confirmed that, regardless of the types of stimulus, all living organisms exhibit the same types of physical reactions if the organisms are exposed to harmful stimuli; he named such harmful stimuli as "stressors," and the series of physical reactions as "general adaptation syndrome (GAS)." In his definition, stress is the state that occurs when an organism is physically reacting to the stressors, and the magnitude of the stress is evaluated on the basis of the intensity of physiological stress responses. We follow Selye's definition in general when we use "physiological stress" in this study.

Cardiovascular response represented by the fluctuation of RRIs is one of the expressions of physical responses against stressors. The fluctuation of RRIs reflects the process of GAS - the activities of the autonomic nervous system (ANS). When a person is exposed to stressors, the sympathetic nervous system (SNS), which is one of the two divisions of the ANS, is activated and the parasympathetic nervous system (PNS), the other division of ANS, is suppressed to fight or adapt to the stressors, whereas when a person is relaxed, SNS is suppressed and PNS is activated $[2,5,37]$. The activation of SNS mitigates the fluctuation of RRIs and decreases HRV, whereas the activation of PNS causes the increase in HRV [4, 50]. HRV immediately reacts to the appearance of stressors, such as the change in temperature, noise, and the concentration of carbon monoxide in the atmosphere [32]. Because of these characteristics, HRV has been regarded as one of the indicators for measuring the physiological stress level. 
Physiological Stress, Psychological Stress, and Affective States

Whereas physiological stress has been prescribed in the objectively observable causality between stressors and organisms, psychological stress is a more complicated notion, which emerges in the dynamic processes of mutual interaction between a person and the environment [23]. Lazarus [24] and Lazarus and Folkman [23] proposed a theoretical schematization of psychological stress, whose main components are "antecedents," "processes," and "outcomes" (Fig. 2).

As shown in Fig. 2, a psychological stressor emerges as a result of the appraisal of the interaction between personality and the social-environmental situation. If a person appraises that a situational demand might be a "threat" for $\mathrm{him} / \mathrm{her}$, the person considers the demand as a psychological stressor. Once a psychological stressor emerges, people choose coping strategies against it. If the chosen strategies work, the negative effects of the psychological stress are mitigated. The emergence of psychological stressors changes the physiological states, such as the change in HRV, and the psychological states, such as affective states. This phenomenon is called "immediate effect" of psychological stressors. Both the physiological and the psychological demands possibly cause both the physiological and the psychological change, respectively, in people as the immediate effects of psychological stressors, as a result of the interaction among people, environment/situation, and the people's appraisal and coping process (Fig. 2). If people could never buffer or get rid of the stressors, it could trigger a change in people's well-being. Therefore, it seems reasonable to consider HRV, which is an outcome of physiological stress, as a substitute variable for the affective states of people. As a matter of fact, scholars have reported a negative correlation between "stress" and "well-being." For example, Schiffrin and Nelson [31] reported a significant relationship between perceived psychological stress level and both cognitive and affective well-being, and Suh et al. [42] reported a significant negative correlation between psychological stress level anticipated by the occurrence of significant life events and cognitive well-being. Furthermore, a significant relationship between HRV and psychometrics such as perceived stress level and depression has been reported [1, 22, 28, 45]. Trimmel [45] also reported a significant positive correlation between HRV and the frequency of the appearance of positive moods in a day; the relationship, however, between daily transactions of affective states and HRV has not yet been examined. The investigation into the relationship between HRV and affective well-being is still at an early stage, so this study aims to shed light on this aspect.

\section{Whose Affective Well-Being is in Question?}

Japan has been experiencing a rapid decline in mortality and fertility since the end of World War II [27]. Owing to this trend, the rate of the population aged over 65 years old in the total population reached $27.2 \%$ in 2016 , and the annual net change rates of the population have been negative since 2010 [26]. These demographic trends are more remarkable in rural areas. Aging increases the spending on pensions and long-term medical care for elderly people, whereas tax revenue decreases as a result of depopulation [18]. Therefore, the central and municipal governments are

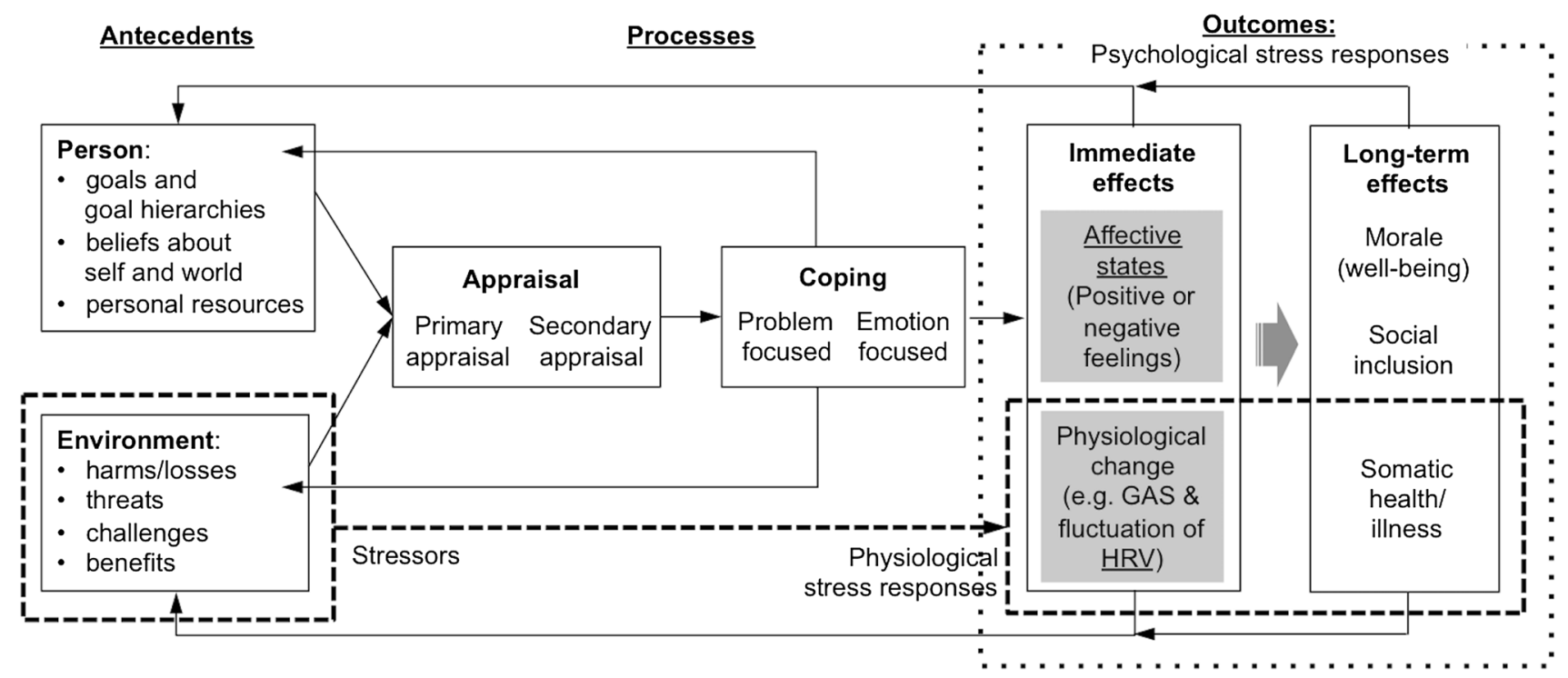

Fig. 2 Relational model of physiological stress, psychological stress, and affective states 
required to reduce their expenditure for administrative services that have maintained the well-being of people. Furthermore, aging and depopulation are also weakening the local communities through the decrease in the number of members.

Social environmental circumstances and situations are the significant factors that could determine people's wellbeing and stress level. Because of the hardship brought about by aging and depopulation, it is anticipated that the well-being of the people, especially in rural areas, will dramatically deteriorate in the near future. However, it is not well understood of how these phenomena actually distort people's daily life and how much their well-being is changed by these phenomena. Therefore, we attempt to focus on an aging, depopulating, and rural village as a field of empirical study for measuring affective well-being. By applying our new approach for the measurement, we not only discuss how well the physiological stress level could work as a substitute variable for affective states but also assess how aging and depopulation are affecting the affective well-being and stress level of the people in the village.

\section{Methodology}

\section{Community for a Case Study}

A small village was identified as the focus field of this case study. The village is located on a mountainous region of Uonuma City in Niigata Prefecture, which is one of Japan's most famous areas for heavy snowfall (Fig. 3). In this village, there are currently 105 residents in 47 households form a robust community [47]. Most of the community members who work have engaged in seasonal jobs. From spring to autumn, they have engaged in hunting and agriculture through the ages. In winter, they make a living by working at small-scale tourism facilities, mainly for skiing, in their village, or by engaging in side jobs.
Thanks to the success in harvesting edible wild plants from the mountains, the village was at its economic peak from 1970s to 1990s. However, since the 1990s, the population has been aging and decreasing in the community owing to the lack of decent employment opportunities for the younger generations. In 2015, whereas the population of "age lower than 30 " groups was only 7 , the percentage of "age 65 and older" groups was over $45 \%$. Furthermore, the total population in 2015 was about $67 \%$ of the total population in 2005 [48].

In this research, surveys were conducted on the adult residents in this community. The surveys were conducted in both summer (from August 31 to September 6 in 2015) and winter (from January 15 to 22 in 2016) because the living environments of the community in these seasons are largely different (Fig. 3). This study was approved by the Tokyo Institute of Technology Research Ethics Committee, and the surveys were conducted with prior written consent of all participants.

\section{Measures and Apparatus}

To measure the affective well-being of the people in the community based on the combination of DRM and HRV measurement, we recommended them to use a wearable device. For this end, two types of measures and apparatus were prepared: (1) DRM for understanding the lifestyles and affective states of the people, and (2) a monitoring system consisting of a wearable device and a smartphone for recording a-day-long RRI data.

\section{The Day Reconstruction Method}

For the implementation of DRM, we followed the procedures proposed by Kahneman et al. [20]. First, respondents answered a questionnaire about their demographic information. Second, the respondents were requested to recall the sequence of episodes - a set of a combination of "activities," "location," and "people with whom"- that they
Fig. 3 Distant views of the village (left summer, right winter)

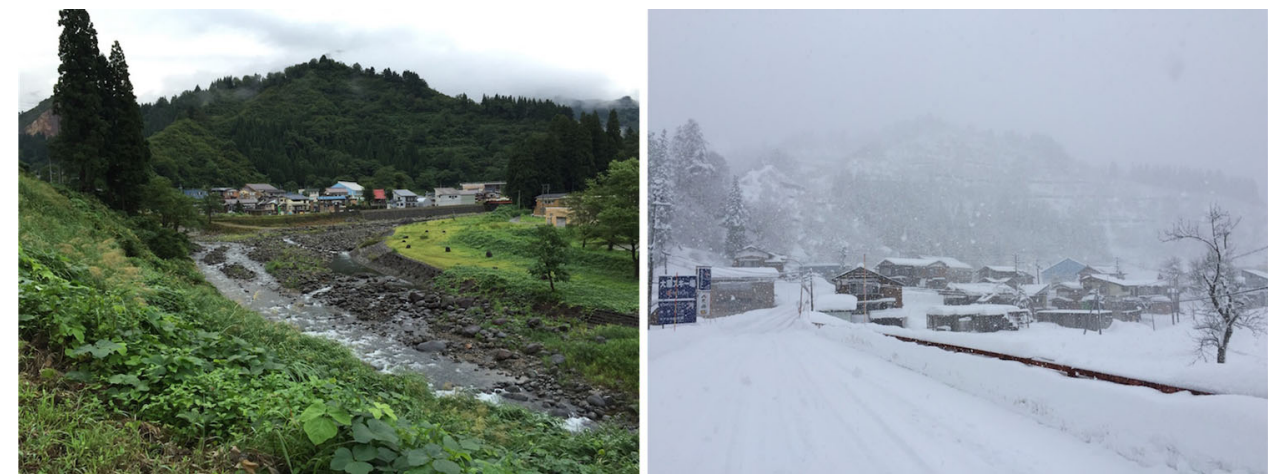


experienced in the previous day. The participants were asked to answer the previous day's episodes from getting up to going to bed. Lastly, the respondents were asked to recall and indicate their affective states in each episode. To avoid excessive burden on the people when indicating their episodes (i.e., asking them to indicate the episodes at minutescale level makes recalling them extremely burdensome) and to ensure the validity of the HRV measurement by the wearable device (see also "Apparatus for HRV Measurement" section and the "Appendix"), we used $15 \mathrm{~min}$ as a minimum duration of the episodes in this study.

Following Kahneman et al. [20], we asked the participants to use 12 types of affect descriptors to describe their affective states (Fig. 4). The scales of the descriptors range from 0 ("not at all") to 6 ("very much"). To explain the affective states intelligibly, we introduced the concepts of "positive affect," "negative affect," "net affect," and "Uindex" developed by Kahneman et al. [20]. Net affect is the indicator that can explain not only the balance of positive and negative affects but also the intensity of them. However, the absolute values of net affect are strongly affected by the personality of the participants, and it is not easy to compare the scores of net affect between the people. When some participants tend to choose extremely high scores, we cannot judge whether the difference is caused by the "real" pleasure/hardship of the episodes or by their personality. To overcome this problem, Kahneman et al. [20] developed the U-index indicator, where " $U$ " means unpleasant or undesirable. To calculate U-index, we compared the maximum scores in the positive and negative descriptors in each episode. If the maximum scores in the negative descriptors were higher than the maximum scores in the positive descriptors, we distinguished the episode as an episode with an unpleasant affective state. U-index is the ratio of the time that the participant spent with an unpleasant affective state in a day. This indicator can explain the predominance of negative affect in each episode without considering whether the participants tend to answer modestly or extremely [21].

\section{Apparatus for HRV Measurement}

Using a Holter electrocardiograph (ECG) is one of the ideal ways to precisely record a-day-long ambulatory data of RRIs [3, 39, 46]. However, a Holter ECG requires the participants to paste electrodes on the proper positions on their skin and prohibits them from taking showers on assay days. Because of these burdens, some researchers prefer other apparatuses, even though the alternatives are less accurate than the Holter ECG. The most popular apparatuses that have been used are heart rate monitor chest straps. These chest straps have been preferably used in many researches studies for evaluating physiological stress levels [5, 7, 41]. However, we still deemed the chest straps to be impractical for a-day-long recording in local communities because the electrode area of the strap should be moist before it can be used, and it seems to be unpleasant for participants to be asked to wear the strap for long-term use. To minimize the burdens on the participants, we used a wristband-type wearable device, which mounts a PPG.

A wearable device with a PPG monitors the light intensity reflected from the tissues moving along with the pulse rate. Because of its compactness and adaptivity to the human body, PPG is preferably mounted on wristband-type wearable devices, and it permits users to track the cardiovascular activities in a noninvasive way. In this research,
Fig. 4 Affect descriptors in this study

\section{Affect descriptors}

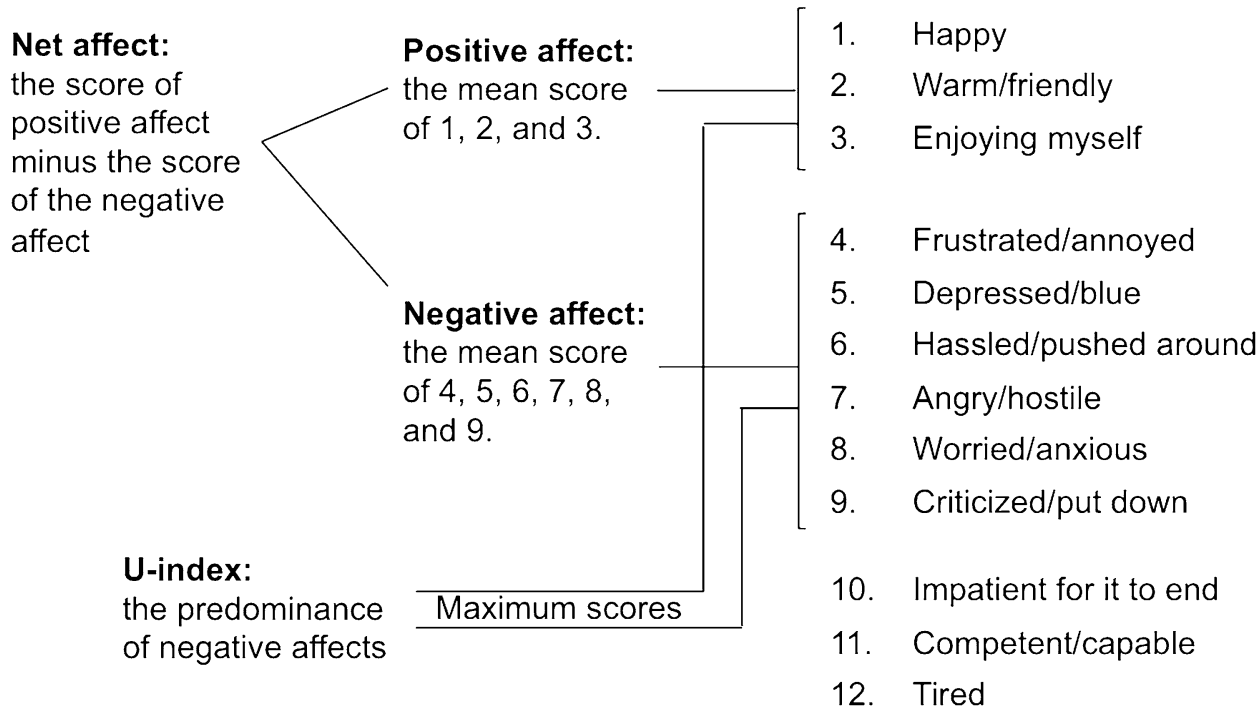


we decided to use a commercially available PPG sensor ("MIO Fuse") developed by Physical Enterprises Inc. (MIO Global) in collaboration with Philips (Fig. 5). MIO Fuse has a PPG sensor named Philips Optical Heart Rate Monitoring Module (OHRM), with enough battery capacity to measure a-day-long RRIs, and a 3-atm waterproof structure.

The accuracy and reliability of PPG have been tested based on the comparison of the short-term HR with ECG or traditional chest strap devices [29, 38, 49]. The results supported the validity of the HR recorded by PPG. However, these previous studies have been mainly focused only on HR measurement or short durational measurement of HRV, and there are no supportive or unsupportive results on the validity of long-durational HRV measurement by a PPG. It is known that a PPG on a wrist is vulnerable to motion artifacts and pressure disturbances, and, sometimes, the recorded data are averaged/smoothed to eliminate such disturbances [43], which makes it difficult to get the accurate scores of HRV from PPG. Therefore, we need to propose a way, with consideration of the limitations of the PPG, to get enough reliable results from HRV measurement to capture the fluctuation of people's physiological stress level.

There are several methods for HRV measurement. The Task Force of the European Society of Cardiology and the North American Society of Pacing Electrophysiology [44] have categorized the methods into two groups: time-domain methods and frequency-domain methods. However, we could not adopt the frequency-domain methods, which require accurate RRI data, because the RRI data recorded by MIO Fuse are possibly averaged/smoothed. Therefore, we chose to use the Lorenz plot area square (LP-area-S) method, which is a representative time-domain method and enables us to visually detect outliers by showing the recorded RRI data in a Lorenz plot [50]. To evaluate the LP-area-S, at first, we plotted the dots in a plane coordinate system, where the $x$-coordinates of the dots are the $n$th RRI and the $y$-coordinates of the dots are the $(n+1)$ th RRI. In general, the plotted dots form an elliptical shape. In this method, the standard deviation of RRIs projected on the $y=x$ axis is considered as the long side of the ellipse, and the standard deviation of RRIs projected on the $y=-x$ axis is considered as the short side of the ellipse (Fig. 6). The area square of this virtual ellipse is called LParea-S. We used 15 min of LP-area-S as a unit according to the result of the validity test (see the "Appendix").

The wearable device used for this research sends the measured RRI data every second to a smartphone through Bluetooth Low Energy (BLE). In this research, an Androidbased smartphone (Moto G, produced by Motorola Mobility LLC) and an application software developed by the authors were used to receive, monitor, and record the raw RRI data. We developed the software by modifying an open-source software (MIT License) named "BLE Heart rate variability demo" developed by Erjanti and Rudenko [15], and the program can store and export data files, which contain the time series data of RRIs.

\section{Procedures of Data Collection and Analysis}

\section{Data Collection}

The participants in the survey were asked to indicate their demographic characteristics such as age, gender, annual
Fig. 5 A MIO Fuse and its PPG sensor

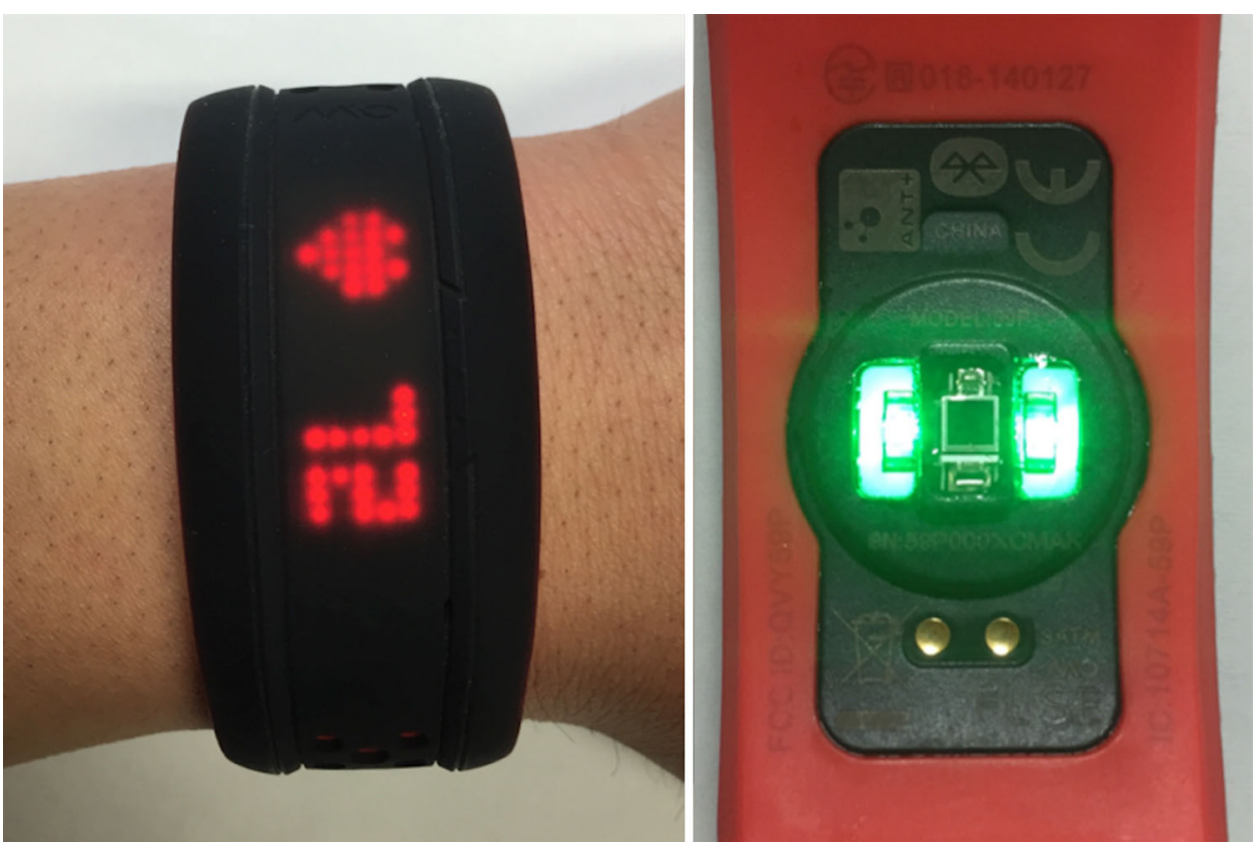




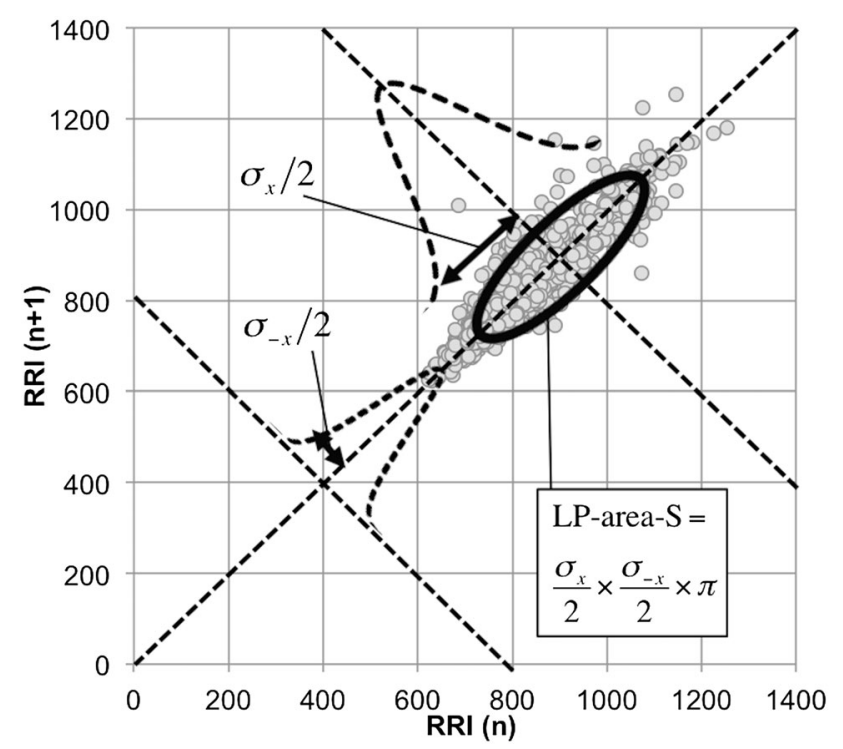

Fig. 6 Lorenz plot area square of RRI

household income, marital status, duration of residence (year), and residence status. It required 2 days to finish all procedures of the data collection (DRM and HRV). In the early morning, we visited the homes of the participants to equip them with the wearable devices and the smartphones for measuring a-day-long RRIs, and revisited after the dinner time to collect the devices. In the next day, we visited again the participants who finished the HRV measurement on the previous day, and performed the DRM and a questionnaire survey through face-to-face conversation.

\section{Assessing the Affective Well-Being in the Community}

On the basis of the results of the questionnaire survey and the DRM, we compiled the demographic characteristics of the participants and outlined the features of their lives in terms of their time use. To indicate the level of affective well-being in the community, we calculated the mean scores of net affect and U-index of all participants' whole episodes in each season. For a more detailed assessment, the scores of LParea-S were assigned to each collected episode by processing the time-series data of RRIs, and the episodes were then disaggregated in terms of their types of activities, locations, and people with whom. The items of classification of each domain were given based on the Harmonized European Time Use Survey Guideline [16]. The mean scores of net affect, the mean scores of LP-area-S, and the time duration of the situation were calculated for each item, respectively. Furthermore, the information was visualized in bubble charts to simplify the interpretation of the assessment.
Investigating the Relationship Between Affective States and Physiological Stress Levels

To investigate the relationship between affective states and physiological stress levels, we calculated the Pearson productmoment correlation coefficients between the scores of each affective descriptor and LP-area-S for all collected episodes in the community. In addition, to examine the interpretability of the physiological stress level, as a substitute for affective states, we applied a receiver operating characteristic (ROC) curve analysis on LP-area-S and on the unpleasantness of the episodes. As described in "The Day Reconstruction Method" section, if the maximum scores of the negative affects were larger than the maximum scores of the positive affects in an episode, the episode was distinguished as an "unpleasant" episode. In this ROC analysis, we aimed to evaluate the performance of the scores of LP-area-S in the episodes as the separator scales to discriminate between unpleasant episodes and not-unpleasant episodes. In the discrimination, there was a trade-off between the true-positive fraction (TPF) and the false-positive fraction (FPF). The ROC curve is a plot of TPF versus FPF across the varying cut-off score of LP-area-S. Figure 7 is an example that shows that separator $\mathrm{A}$ is better than separator $\mathrm{B}$ for discriminating certain states. The closer to the upper left-hand corner the ROC curve locates, the better the separator scale discriminates. If the ROC curve is on a diagonal line, the discrimination by the separator scale is equal to the random discrimination. Therefore, the area under the ROC curve (AUC) was used to numerically express the performance of the separators. The AUC ranged from 0.5 to 1 . In this study, if the score of the AUC is close to 1, LP-area-S was regarded as a good indicator that could be used to predict that the person was unpleasant or not in certain episodes. If the AUC was close to 0.5 , it could be concluded that LP-area-S was not a sufficient separator scale and, therefore, we could not simply regard the physiological stress level as a substitute for affective states.

\section{Results}

\section{Assessment of Affective Well-Being in the Community}

\section{Demographic Characteristics of the Participants}

We collected the data from the surveys for 10 participants in the summer of 2015 and for 13 participants in the winter of 2016 in the focused village, respectively. Seventeen different people, out of 105 individuals in the village, participated, and six people participated in the survey for 


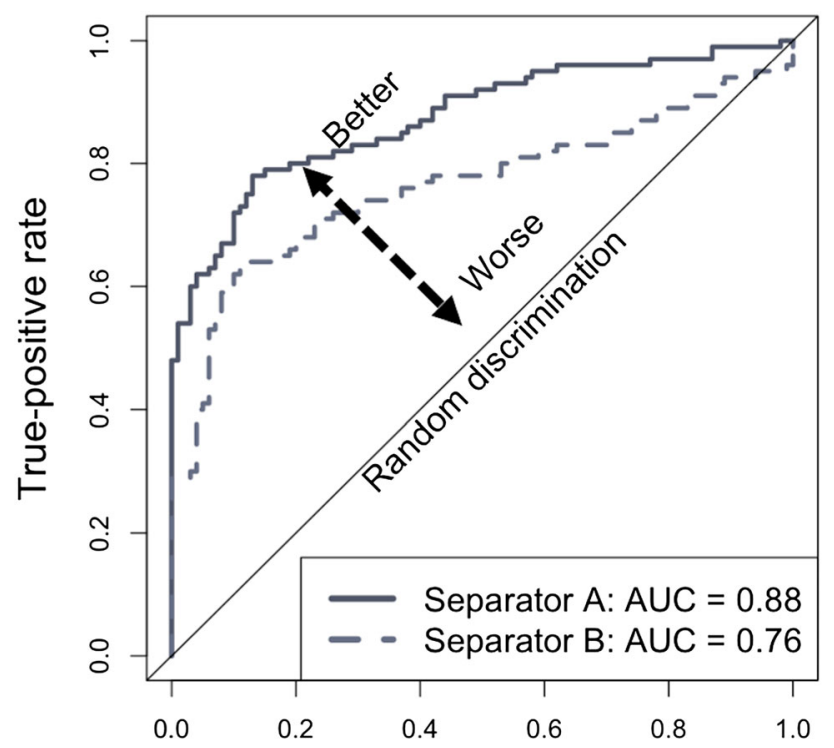

False-positive rate

Fig. 7 ROC curves of two diagnostic tasks (test A and test B)

both seasons. The demographic characteristics of the participants are shown in Fig. 8. More than $40 \%$ of the participants were 60 years old or over. The male-to-female ratio was about 1:1. Most of the participants were married, grew up locally, and were living in privately owned houses. We could collect the data of annual household income from about $60 \%$ of the participants and certified that most of the people aged over 65 years were pensioners.

\section{Outline of the Time Use in the Community}

Through the DRM, we observed 163 and 194 waking hours and collected 165 and 184 episodes in the summer and winter from 10 and 13 participants, respectively. The general outline of the participants' time use in the community is shown in Table 1. It seems reasonable that the people who participated in the summer survey reported more types of "activities," "locations," and "people with whom" than the people who participated in the winter survey, although the differences were not statistically significant except for "people with whom." However, the mean duration of one episode was about an hour in both seasons.

We successfully recorded about $8.5 \mathrm{~h}$ of RRI data on average with the wearable device from all participants. The recording duration covered more than $50 \%$ of the waking hours on average. The coverage of recording was not $100 \%$ because there were some unrecorded episodes in the early morning and late evening. To make matters worse, one

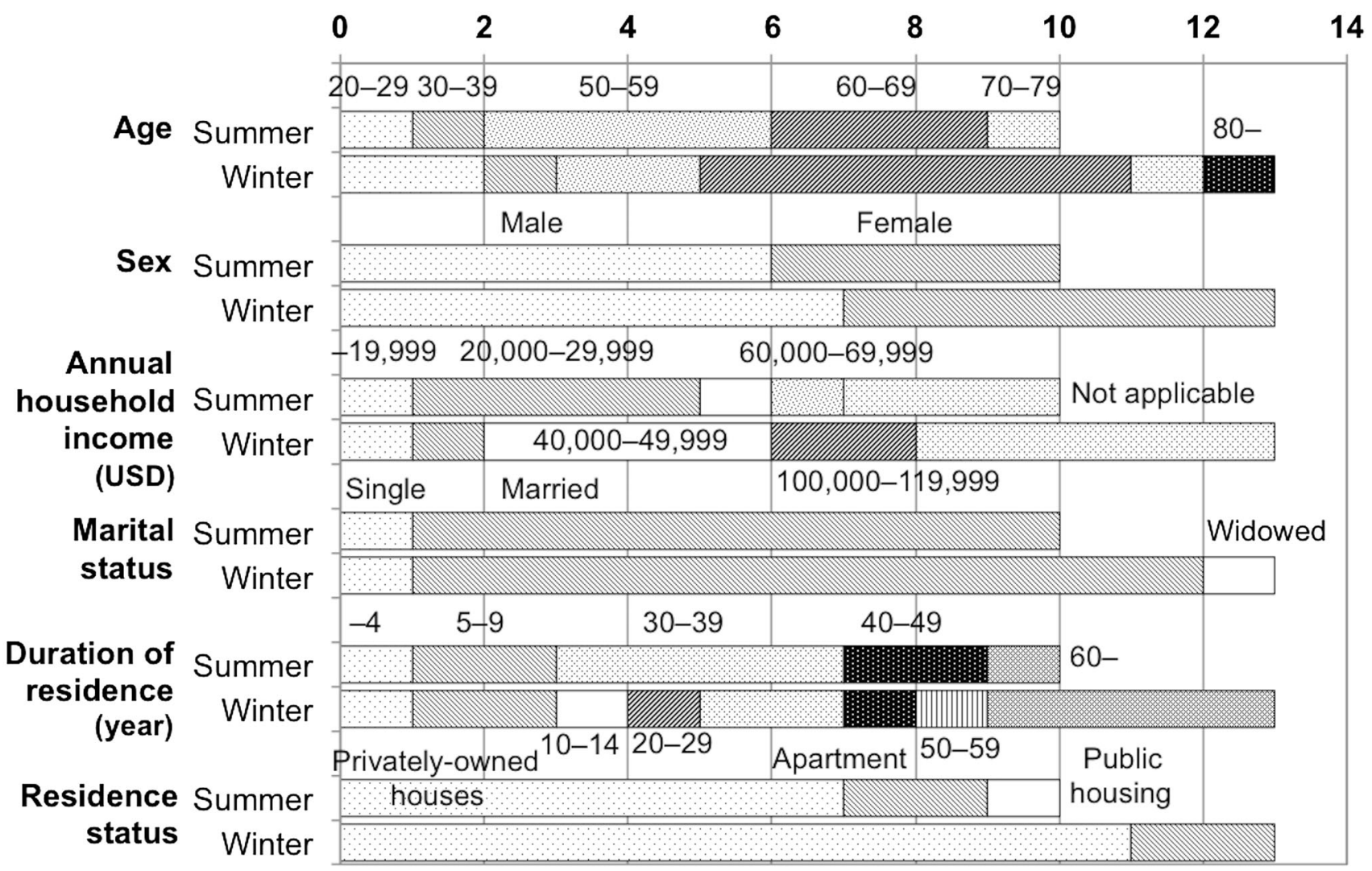

Fig. 8 Demographic characteristics of the participants in the village (1 USD is nearly equal to 100 JPY) 
Table 1 Summary of the time use of a day
Table 2 Ratings of affective scores in each season

\begin{tabular}{|c|c|c|c|c|c|c|c|c|c|}
\hline & \multicolumn{4}{|c|}{ Summer $\left(n_{\mathrm{s}}=10\right)$} & \multicolumn{4}{|c|}{ Winter $\left(n_{\mathrm{w}}=13\right)$} & \multirow[t]{2}{*}{$p$} \\
\hline & Total & Mean & SD & Range & Total & Mean & SD & Range & \\
\hline Waking hours (h) & 163 & 16.3 & 1.04 & $14-18$ & 194 & 14.9 & 2.63 & $11-20$ & 0.15 \\
\hline Number of episodes & 165 & 16.5 & 5.28 & $9-25$ & 184 & 14.2 & 4.08 & $8-22$ & 0.26 \\
\hline Duration of an episode (h) & - & 0.99 & 0.87 & $0.25-4$ & - & 1.01 & 0.82 & $0-4$ & 0.24 \\
\hline \multicolumn{10}{|l|}{ Number of the variations of } \\
\hline Activities & 16 & 6.70 & 1.49 & $5-9$ & 16 & 7.62 & 2.06 & $4-10$ & 0.23 \\
\hline Locations & 12 & 3.70 & 1.62 & $2-7$ & 9 & 2.77 & 1.17 & $1-5$ & 0.16 \\
\hline People with whom & 13 & 5.00 & 1.73 & $2-8$ & 9 & 3.77 & 0.83 & $2-5$ & 0.04 \\
\hline Recording duration (h) & 91.8 & 9.18 & 3.63 & $1.5-14$ & 104 & 8.00 & 4.45 & $0.8-13$ & 0.51 \\
\hline Coverage of recording & 0.57 & 0.57 & 0.23 & $0.09-0.89$ & 0.54 & 0.54 & 0.31 & $0.06-0.94$ & 0.79 \\
\hline
\end{tabular}

The $p$ value is for a two-sided $t$ test of difference between the scores of the two surveys in both summer and winter. Coverage of recording is the ratio of the recording duration by the wearable device to waking hours

\begin{tabular}{|c|c|c|c|c|c|c|}
\hline \multirow[t]{2}{*}{ Affect descriptors } & \multicolumn{3}{|c|}{ Summer } & \multicolumn{3}{|c|}{ Winter } \\
\hline & Mean & SD & Frequency $(\%)$ & Mean & $\mathrm{SD}$ & Frequency $(\%)$ \\
\hline 1. Нарpy & 1.65 & 1.97 & 46.3 & 1.64 & 1.91 & 55.2 \\
\hline 2. Warm/friendly & 1.29 & 1.41 & 53.0 & 1.27 & 1.66 & 48.6 \\
\hline 3. Enjoy myself & 1.17 & 1.60 & 42.1 & 1.61 & 1.87 & 53.6 \\
\hline 4. Frustrated/annoyed & 0.32 & 0.86 & 15.9 & 0.13 & 0.51 & 7.73 \\
\hline 5. Depressed/blue & 0.85 & 1.72 & 32.3 & 0.36 & 1.00 & 14.9 \\
\hline 6. Hassled/pushed around & 0.63 & 1.13 & 35.4 & 0.36 & 0.90 & 17.1 \\
\hline 7. Angry/hostile & 0.15 & 0.81 & 4.88 & 0.13 & 0.65 & 6.08 \\
\hline 8. Worried/anxious & 0.67 & 1.49 & 22.6 & 0.55 & 1.14 & 24.3 \\
\hline 9. Criticized/put down & 0.17 & 0.57 & 11.6 & 0.08 & 0.45 & 3.31 \\
\hline 10. Impatient for it to end & 0.22 & 0.73 & 9.76 & 0.45 & 1.16 & 17.7 \\
\hline 11. Competent/capable & 1.70 & 2.09 & 48.2 & 1.75 & 2.01 & 53.0 \\
\hline 12. Tired & 0.65 & 1.06 & 37.2 & 1.12 & 1.64 & 43.1 \\
\hline Positive & 1.37 & 1.28 & 67.1 & 1.51 & 1.65 & 66.9 \\
\hline Negative & 0.47 & 0.66 & 56.7 & 0.27 & 0.53 & 33.1 \\
\hline Net affect & 0.90 & 1.68 & 60.4 & 1.24 & 1.84 & 63.5 \\
\hline U-index & 0.31 & & & 0.20 & & \\
\hline
\end{tabular}

The U-indexes in each season are on the bottom line. The heading "Frequency (\%)" expresses the percentage of the number of episodes rated above zero in all episodes. If there was a significant difference between the scores in the summer survey and those in the winter survey with $95 \%$ confidence interval, the affective descriptors and their mean scores are displayed in bold participant in the summer survey forgot to wear the wearable device again after taking a morning bath and two participants in the winter survey did not properly carry the smartphones, resulting in the disconnection between the wearable device and the smartphone. We failed to record RRI data with enough duration from these three participants.

\section{Affective Well-Being, Stressors and Time Use in the Community}

The mean scores of net affect calculated from all reported episodes were 0.90 and 1.24 , in the summer and the winter surveys, respectively. In both seasons, the reported scores of positive affect descriptors were higher than those of negative affect descriptors. In the summer survey, the scores of the negative affects, such as "Frustrated/annoyed," "Depressed/blue," and "Hassled/pushed around," were significantly higher than those in the winter, and the U-indexes indicated that the participants in the summer survey tended to be predominated by negative affects more than the participants in the winter, although the intensity of their positive affects was not significantly different between the two seasons except for "Enjoy myself" (Table 2).

To understand more the situational differences of the affective states and the physiological stress levels in the 
Table 3 Mean scores of net affect and LP-area-S by situation in the summer

\begin{tabular}{|c|c|c|c|c|c|}
\hline \multirow[t]{2}{*}{ Situations } & \multicolumn{2}{|c|}{ Mean scores of each situation } & \multirow[t]{2}{*}{ Mean hours/day } & \multirow[t]{2}{*}{ Sample reporting } & \multirow{2}{*}{$\begin{array}{l}\text { Recording duration by } \\
\text { the wearable device }(\%)\end{array}$} \\
\hline & Net affect & LP-area-S & & & \\
\hline \multicolumn{6}{|l|}{ Activity } \\
\hline Childcare & 2.00 & 1060 & 0.22 & 1 & 100 \\
\hline Chatting & 1.89 & 2030 & 0.79 & 3 & 83 \\
\hline Eating & 1.78 & 2020 & 3.52 & 10 & 50 \\
\hline Cooking/cleaning & 1.68 & 1750 & 0.90 & 2 & 15 \\
\hline Entertainment and culture & 1.67 & - & 0.16 & 1 & 0 \\
\hline Using computer (for fun) & 1.64 & - & 0.30 & 2 & 0 \\
\hline Relaxing & 1.51 & 2910 & 2.43 & 7 & 52 \\
\hline Watching TV & 1.29 & 1270 & 0.71 & 4 & 4 \\
\hline Job & 0.88 & 2210 & 7.77 & 10 & 69 \\
\hline Participatory activity & 0.80 & 1730 & 0.57 & 3 & 76 \\
\hline Personal care & 0.76 & 4660 & 1.61 & 8 & 53 \\
\hline Traveling & 0.39 & 3240 & 1.88 & 7 & 52 \\
\hline Activity related to employment & 0.23 & 1610 & 0.27 & 2 & 40 \\
\hline Shopping & -0.07 & 5540 & 0.14 & 2 & 80 \\
\hline Other house works & -0.67 & - & 0.49 & 2 & 0 \\
\hline Reading books & -0.83 & - & 0.22 & 1 & 0 \\
\hline \multicolumn{6}{|l|}{ Location } \\
\hline Second home & 1.61 & 1860 & 0.27 & 1 & 80 \\
\hline Other people's home & 1.41 & 2140 & 0.95 & 2 & 49 \\
\hline Home & 1.38 & 2560 & 9.55 & 10 & 51 \\
\hline School & 0.78 & 1400 & 0.25 & 1 & 100 \\
\hline Sports arena & 0.78 & 1400 & 0.25 & 1 & 100 \\
\hline Public hall & 0.57 & 2070 & 0.44 & 2 & 63 \\
\hline Working place & 0.51 & 2280 & 4.17 & 4 & 73 \\
\hline Hospital & 0.46 & 6980 & 0.22 & 2 & 75 \\
\hline Traveling by passenger car & 0.38 & 3200 & 1.91 & 7 & 53 \\
\hline Shop & 0.33 & 5540 & 0.16 & 2 & 67 \\
\hline Traveling on foot & 0.33 & 1430 & 0.27 & 1 & 60 \\
\hline Business trip destination & -0.42 & 1280 & 0.11 & 1 & 100 \\
\hline \multicolumn{6}{|l|}{ People with whom } \\
\hline Children (under 10 years) & 3.35 & 1290 & 0.76 & 2 & 64 \\
\hline Other persons known to the respondent & 2.27 & 1520 & 0.87 & 4 & 28 \\
\hline Families in other households & 1.90 & 1970 & 0.14 & 1 & 100 \\
\hline Other household members & 1.62 & 1400 & 0.76 & 3 & 61 \\
\hline Alone & 1.44 & 2490 & 5.95 & 10 & 55 \\
\hline Guest/customer & 1.40 & 1370 & 1.04 & 3 & 53 \\
\hline Children (10 years and over) & 1.17 & 1370 & 1.64 & 4 & 30 \\
\hline Friends & 1.01 & 2140 & 3.60 & 6 & 80 \\
\hline Colleagues & 0.63 & 1510 & 1.72 & 3 & 67 \\
\hline Partner & 0.58 & 3720 & 6.25 & 7 & 40 \\
\hline Neighbors & 0.27 & 2080 & 2.24 & 3 & 83 \\
\hline Others & 0.20 & 1750 & 1.23 & 5 & 42 \\
\hline
\end{tabular}

"Mean hours/day" is the average amount of all participants' time spent in the situation, and it is not conditional on engaging in the activity, being in the location, and interacting with people. "Recording duration by wearable device (\%)" is the percentage of the successfully recorded duration by the wearable device in each situation 
community, we calculated the mean scores of "net affect," and "LP-area-S" for each "activity," "location," and "people with whom" reported in each season (Tables 3, 4). We visualized these scores in six bubble charts in Fig. 9. The size of the bubbles represents the mean duration of the time spent by all participants in a situation. The vertical axes represent the mean scores of LP-area-S, whereas the horizontal axes represent the mean scores of net affect. The dotted lines express the mean scores of net affect and LParea-S of all reported episodes in each season. By comparing the scores of each situation with the mean scores of all reported episodes, we could evaluate which situations were more/less positive/negative and stressful.

In the summer, the participants spent most of their time doing a "job," "eating," or "relaxing," at "home," at a "working place," or by "traveling by passenger car" with

Table 4 Mean scores of net affect and LP-area-S by situation in the winter

\begin{tabular}{|c|c|c|c|c|c|}
\hline \multirow[t]{2}{*}{ Situations } & \multicolumn{2}{|c|}{$\begin{array}{l}\text { Mean scores of each } \\
\text { situation }\end{array}$} & \multirow[t]{2}{*}{ Mean hours/day } & \multirow[t]{2}{*}{ Sample reporting } & \multirow[t]{2}{*}{ Recording duration by wearable $(\%)$} \\
\hline & Net affect & LP-area-S & & & \\
\hline \multicolumn{6}{|l|}{ Activity } \\
\hline Childcare & 3.00 & 2230 & 0.08 & 2 & 50 \\
\hline Eating & 2.46 & 3940 & 4.35 & 13 & 41 \\
\hline Entertainment and culture & 2.38 & 4480 & 1.12 & 5 & 38 \\
\hline Chatting & 2.08 & 3200 & 1.13 & 7 & 61 \\
\hline Watching TV & 2.08 & 3610 & 4.19 & 11 & 49 \\
\hline Relaxing & 1.93 & 3030 & 2.75 & 11 & 71 \\
\hline Napping & 1.56 & 1510 & 0.29 & 4 & 33 \\
\hline Playing sports & 1.47 & 2340 & 0.40 & 3 & 62 \\
\hline Cooking/cleaning & 1.41 & 3720 & 1.65 & 8 & 56 \\
\hline Shopping & 1.11 & 1620 & 0.06 & 2 & 67 \\
\hline Traveling & 1.01 & 2320 & 0.75 & 9 & 38 \\
\hline Personal care & 0.91 & 2540 & 0.56 & 8 & 24 \\
\hline Reading books & 0.75 & 1390 & 0.31 & 1 & 75 \\
\hline Using computer (for fun) & 0.31 & - & 0.38 & 1 & 0 \\
\hline Job & 0.18 & 3480 & 3.50 & 8 & 80 \\
\hline Other house works (snow removal) & -0.17 & 2120 & 0.19 & 4 & 10.0 \\
\hline \multicolumn{6}{|l|}{ Location } \\
\hline Traveling on foot & 2.83 & 960 & 0.04 & 1 & 50 \\
\hline Other people's home & 2.38 & 1100 & 0.15 & 2 & 50 \\
\hline Home & 1.96 & 3150 & 9.87 & 12 & 43 \\
\hline Amusement facilities & 1.50 & 1700 & 0.17 & 1 & 100 \\
\hline Sports arena & 1.44 & 3770 & 0.23 & 2 & 33 \\
\hline Second home & 1.41 & 6360 & 0.58 & 2 & 70 \\
\hline Traveling by passenger car & 0.79 & 2420 & 0.65 & 7 & 41 \\
\hline Shop & 0.67 & 1770 & 0.12 & 1 & 100 \\
\hline Working place & 0.04 & 3500 & 3.44 & 7 & 87 \\
\hline \multicolumn{6}{|l|}{ People with whom } \\
\hline Children (10 years and over) & 3.89 & 2230 & 0.52 & 2 & 7 \\
\hline Friends & 2.61 & 4260 & 1.23 & 9 & 77 \\
\hline Others & 2.17 & - & 0.15 & 1 & 0 \\
\hline Partner & 1.95 & 3240 & 5.21 & 9 & 39 \\
\hline Families in other households & 1.64 & 7140 & 0.56 & 3 & 62 \\
\hline Alone & 1.49 & 3140 & 5.73 & 12 & 57 \\
\hline Other household members & 1.25 & 2200 & 1.67 & 4 & 36 \\
\hline Colleagues & 0.27 & 3210 & 2.81 & 6 & 84 \\
\hline
\end{tabular}

Please refer to the notes in Table 3 

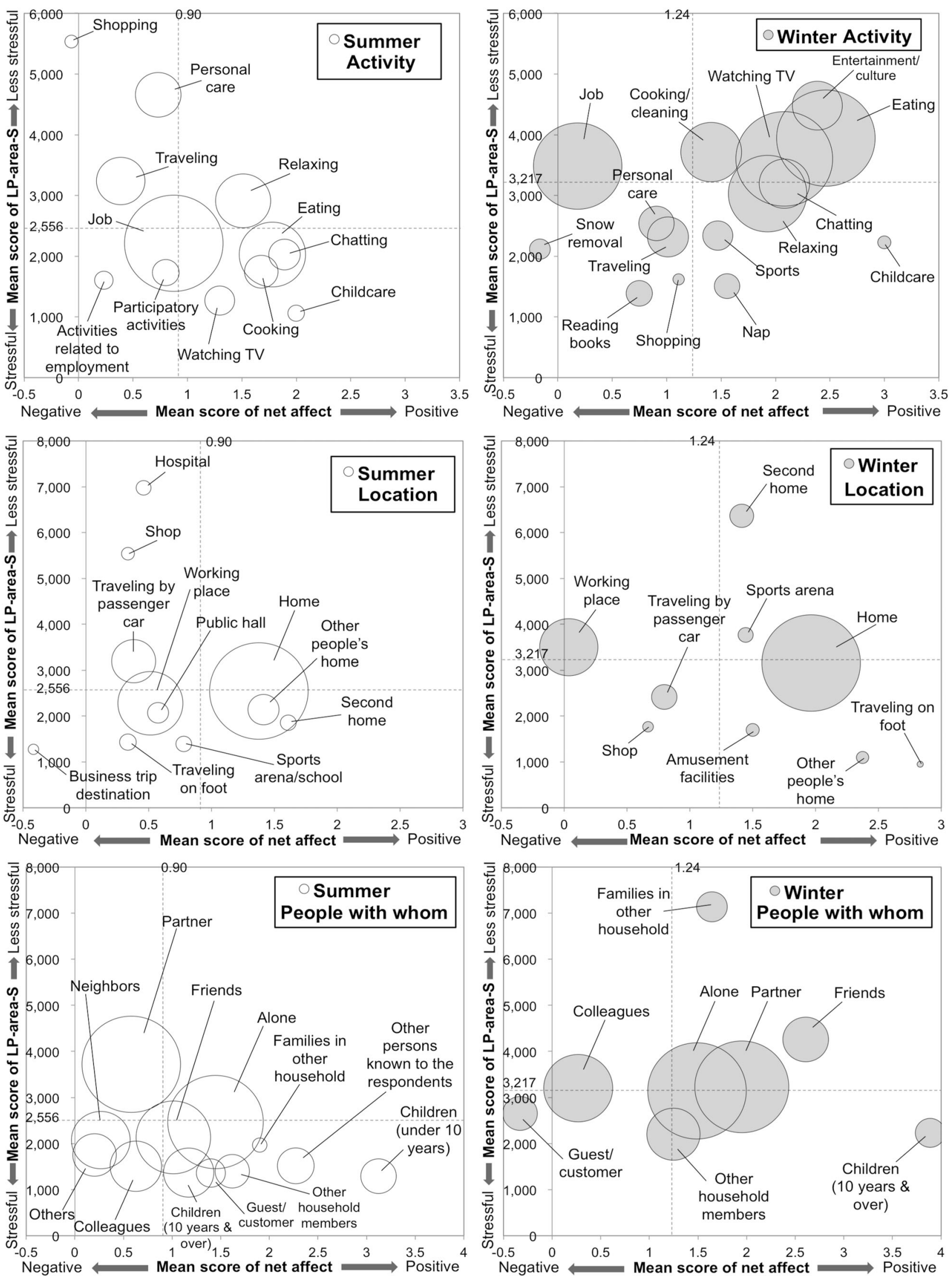
4Fig. 9 The net affect, LP-area-S, and time-spent duration in each situation in the village. Notes The vertical dotted lines indicate the mean scores of net affect ( 0.90 in the summer and 1.24 in the winter), whereas the horizontal dotted lines indicate the mean scores of LParea-S (2560 in the summer and 3220 in the winter) of all reported episodes in each season

"friends," "partner," or "alone." Negative affect dominated only three activities_- "shopping," "other housework," and "reading books" —and one location"business trip destination." People were relatively positive and relaxed when they were "relaxing," but they were relatively negative and stressed when they were doing a "job," a "participatory activity," doing "activities related to employment"; being at a "working place" or at a "public hall"; "traveling on foot," or "business trip destination"; and being with "neighbors," "colleagues," or "others" who are not known to the participants. There were some relatively positive but stressful situations such as doing "childcare," "chatting," or being with children or friends. Contrary to this, there were some negative but relaxing situations such as doing "personal care," "traveling," and being with their "partners."

In the winter, the participants spent most of their time doing a "job," "watching TV," "eating," or "relaxing"; being at "home" or at a "working place"; and being with a "partner," "colleagues," or "alone." Negative affects dominated only one activity_- "other house works," which was snow removal from their houses. People were relatively positive and relaxed when they were "eating"; amusing themselves with "entertainment/culture," "watching TV," or "cooking/cleaning"; being at a "second home" or at a "sports arena"; and being with "friends," "partner," or "families in other household." However, they were relatively negative and stressful when they were doing "personal care," "traveling," "shopping," "reading books," or "snow removal"; being at a "shop" or "traveling by passenger car"; and being with a "guest/customer." As with the results of the summer survey, the people were stressed but positive when they were "chatting" or doing "childcare," being at "other people's household," and being with children.

In both seasons, the people tended to spend a long time at home or at a working place in the village, meaning that it was not so common for the participants to go out from the village. They tended to have positive affects at home but did have negative affects at a working place. The common sources of positive affects were doing activities such as "eating," "chatting," "relaxing," and interacting with intimate people such as their family members and friends. Being with children was also a source of positive affects, but the persons were physically stressed when they were
Table 5 Correlation coefficients between LP-area-S and affective states of each episode

\begin{tabular}{lr}
\hline Affect descriptors & \multicolumn{1}{c}{$r$} \\
& LP-area-S \\
\hline 1. Happy & $\mathbf{0 . 3 4}$ \\
2. Warm/friendly & $\mathbf{0 . 2 3}$ \\
3. Enjoy myself & 0.14 \\
4. Frustrated/annoyed & $-\mathbf{0 . 1 6}$ \\
5. Depressed/blue & $\mathbf{- 0 . 1 7}$ \\
6. Hassled/pushed around & $\mathbf{- 0 . 1 5}$ \\
7. Angry/hostile & -0.10 \\
8. Worried/anxious & -0.12 \\
9. Criticized/put down & -0.10 \\
10. Impatient for it to end & 0.00 \\
11. Competent/capable & 0.06 \\
12. Tired & -0.01 \\
Positive affect & $\mathbf{0 . 2 7}$ \\
Negative affect & $\mathbf{- 0 . 2 2}$ \\
Net affect & $\mathbf{0 . 3 0}$ \\
\hline
\end{tabular}

" $r$ " is the Pearson product-moment correlation coefficient. Correlations with a 95\% confidence interval are displayed in bold

doing "childcare." On the other hand, the common sources of negative affects were doing activities such as a "job," "activities related to employment," and "snow removal," although these activities are essential to their lives. Furthermore, the people tended to be physically stressed when they were facing these negative situations. The sources of negative affects could also work as physiological stressors. If aging and depopulation proceed, the sources of positive affects could deteriorate because of the decrease in opportunities for interacting with intimate people, and the sources of negative affects could increase because of the increase in the difficulties of the jobs and their related activities, which physically weaken the people and deteriorate the human resources in the village.

\section{Relationship Between Affective States and Physiological Stress Levels}

Table 5 shows the Pearson product-moment correlation coefficients between LP-area-S and the scores of affective states of the episodes for whole RRI data successfully recorded by the wearable devices from the people who were experiencing the episodes (184 episodes in all reported episodes). There was a significant positive correlation between LP-area-S and positive affects- "happy" and "warm/friendly." On the other hand, there was a significant negative correlation between LP-area-S and three out of the six types of negative affects- "frustrated/ 
annoyed," “depressed/blue," and "hassled/pushed around." There was no correlation between LP-area-S and three "neutral" affects, which were classified into neither positive nor negative affects- "impatient for it to end," "competent/capable," and "tired." As for the correlation coefficients between LP-area-S and "positive affect," "negative affect," and "net affect," there was a negative correlation between physiological stress level and net affect. Although the causality between physiological stress level and affective states is still unknown, the results showed that, if the stress level of people increased, which means a decrease in LP-area-S, the people tended to be predominated by negative affects, and if the stress level decreased, which means an increase in LP-area-S, the people tended to be predominated by positive affects. However, we have to note that the absolute value of the correlation itself was weak, which was, at most, 0.34 between LP-area-S and "Happy."

We examined how efficiently LP-area-S could discriminate whether an episode was unpleasant or not. The ROC curve was used to demonstrate the performance of LP-area-S in detecting unpleasant episodes, and the AUC of LP-area-S was $0.58 \quad(95 \%$ confidence interval, 0.49-0.67) (Fig. 10). The results indicated that the performance of LP-area-S as a separator scale of the affective states-unpleasant or not-was not high enough for effective discrimination, although there are reasonable relationships displayed in Table 5. This result could indicate that we should investigate more or better measurement and analytical methods for physiological stress level.

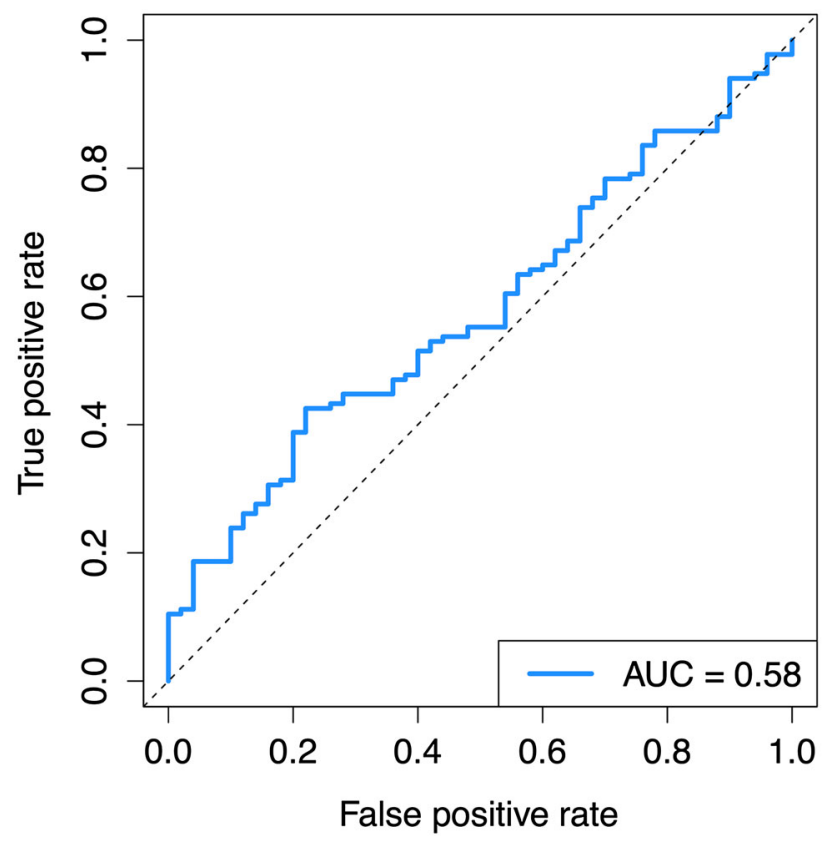

Fig. 10 ROC curve of LP-area-S as a separator scale of "unpleasant" and "not-unpleasant" states
Physiological stress level alone could not explain the affective states comprehensively so that it is important to investigate other factors to substitute for the DRM methods by a decent combination of measurements of RRIs, as in this study, and other unknown influential factors.

\section{Discussions}

In this study, we introduced a new approach for measuring affective well-being based on the combination of DRM and measurement of physiological stress levels by a wearable device of an aging and depopulating village. We investigated the states of the people in the village in terms of people's affective states, stress level, and time use. The interpretability of the physiological stress level indicated by the score of LP-area-S as a proxy of affective states was also examined.

\section{Measuring Well-Being and Stressors in the Aging and Depopulating Village}

According to the results shown in Table 2, the U-indices calculated by the DRM in the village were 0.31 in the summer and 0.20 in the winter, respectively. These scores are higher than the score $(0.18)$ reported by Kahneman and Krueger [21] from 909 workingwomen in Texas. The participants in the village tended to be more negative than the participants in Texas. However, contrary to the general belief that the people in aging and depopulating areas are facing a crisis of well-being, it seemed that the people who participated in this study's survey in the village were not necessarily facing significant hardship because their scores on positive affects were much higher than the scores on negative affects.

After describing the affective status of the community by $\mathrm{U}$-indices, we also assessed the affective well-being by a combination of the DRM and the measurement of physiological stress levels. The results indicated that, in both seasons of summer and winter, the sources of positive affects were doing activities such as "eating," "chatting," and "relaxing," and interacting with intimate people, but doing a "job" or "activities related to employment" and going out from the village were the sources of stress and negative affects for the people in the village. Especially in the winter, snow removal was regarded as a significant negative stressor. If aging and depopulation proceed further in the village, the opportunities for the people to interact with intimate people, mostly neighboring friends, could decrease, and it could be also expected that a job and its related activities could become more stressful and serious sources of negative affects because aging weakens the physical strength of the workers and depopulation reduces 
the human resources for maintaining the business in the village. Furthermore, snow removal, which requires physical strength, could become more stressful for elderly people. Although the current states of affective well-being are generally sound, the findings of this study imply that the current soundness of the community is not sustainable in the future. Aging and depopulation possibly deteriorate the source of positive affects and intensify the negative stressors in the village.

There are still four unresolved points that cannot be overlooked in this research for assessing affective states and physiological stress levels. First, the survey was not conducted on all residents in the village. In addition, we measured the participants' physiological stress and affective states only for 1 day in each season. These limitations could distort our understanding of the actual states of the people in this village. It would be desirable to collect data from most residents in a certain number of days in the village. Second, we could not exclude the effects of the factors that could change the scores of LP-area-S regardless of the people's physiological stress levels, such as gender, age, personality, and therapeutic experiences. For the further studies, we have to collect enough number of samples to control the effects from such factors. Third, there is a problem of how to deal with the situations reported only by some specific persons in some specific occasions. For example, "childcare" is an activity experienced only by one person in each season because the number of children is quite small in the village, but this was an outstanding activity reported as an activity that is physically stressful but has arousing positive affects. In this study, we averaged the scores of net affect and LP-area-S, but the process allowed us to omit some prominent features of the community. Lastly, we only calculated the scores of the physiological stress levels and affective states for each situation. However, the states of the people are determined not only by the combination of the situations at the moment, but also by the effects of context, such as what they experienced before facing the current situations and what they are going to face after the current situations.

\section{Interpretability of HRV as a Proxy of Affective States}

LP-area-S in each episode showed a positive correlation with positive affects and a negative correlation with negative affects. This result suggests that the people in the village tended to be positive when they were relaxed and tended to be negative when they were stressed. It is mostly the same relationship reported in past studies [31, 42]. However, the absolute value of the correlation coefficients itself was not strong enough, at a maximum of 0.34 , with the "happy" descriptor. At the same time, the AUC of the
ROC curve analysis suggested the necessities of further studies to determine whether the people were being unpleasant or not, based on the physiological stress levels produced by the data recorded by the wearable device. Although there were meaningful relationship between the scores of LP-area-S and affective states, there are some challenges to be overcome.

We investigated the reason why there were nonnegligible gaps between the fluctuation of HRV and the affective states through the introduction of the concept model shown in Fig. 2. In the first place, people are not always predominated by negative affects when they are highly physically stressed. For example, even when the people were stressed, they were predominated by positive affects when they were "chatting" or doing "childcare," being at "other people's household," and being with children (Tables 3, 4; Fig. 9). Even people are physically stressed by a certain stressor, if they do not regard the physiological stressor as a "threat"; the physiological stressor is not a psychological stressor and does not arouse any negative affects in the person. Contrary to this, even if a person is not highly physically stressed, if he/she regards the situation as a "threat," he/she will feel psychologically stressed and his/her mood will be negatively affected. Therefore, we need to consider the personality of the people and the characteristics of their processes of appraisal and coping. By considering these points, we could somewhat grasp the tendency of the people's judgment whether the situations are threatening or not, and improve the prediction of their affective states based on HRV measurement. Furthermore, the meanings of the scores of affective states and LP-area-S are different for each person because their interpretation of the affective descriptors and their physiological temperaments are different for each person. In this research, we minimized the effect of the difference in interpretation by introducing the concept of U-index. However, as we described in the previous section, we could not control the difference in physiological temperaments between people because of the small number of participants. Therefore, collecting more samples to do more reliable analysis is the next step of our study.

\section{Compliance with Ethical Standards}

Conflict of interest On behalf of all authors, the corresponding author states that there is no conflict of interest.

\section{Appendix: Reliable Recording Duration of HRV (LP-area-S) by the PPG}

We examined the validity of HRV calculated from the RRI data recorded by MIO Fuse. The authors wore an MIO Fuse on the wrist and Polar H7, which has been used as a 
Fig. 11 Comparison of LParea-S calculated by the data from MIO Fuse and Polar H7
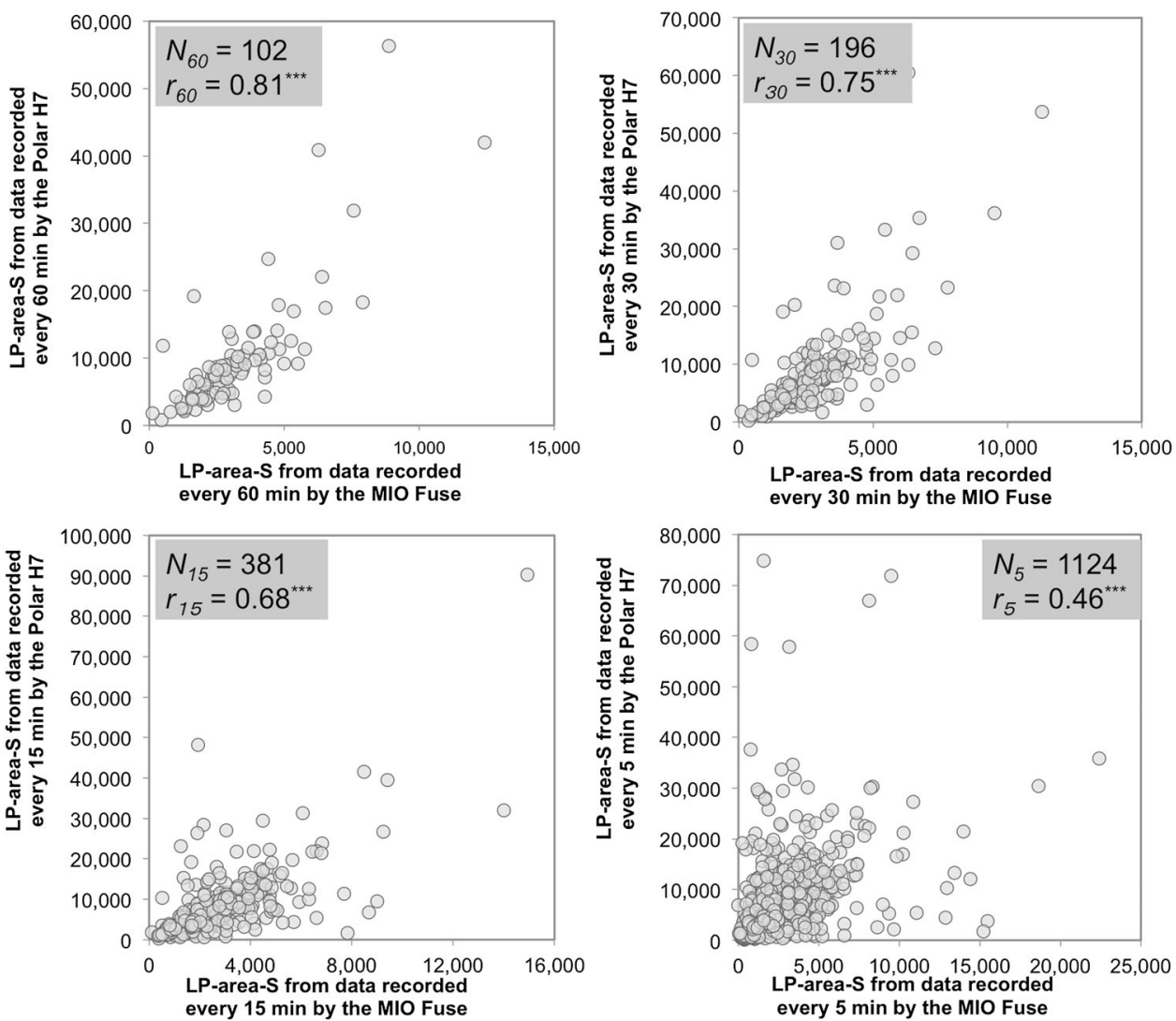

recording device in the other studies, on the chest together, and recorded the RRI data of their waking hours for a week. The measured RRI data were saved in two smartphones. We calculated LP-area-S from RRI data recorded every $5,15,30$, and $60 \mathrm{~min}$ for each device. We investigated the correlation between the LP-area-S of MIO Fuse and that of Polar $\mathrm{H} 7$.

From a 7-days-long recording, we successfully collected 5623-min-long time-series RRI data of MIO Fuse and Polar H7. The LP-area-S of MIO Fuse and that of Polar H7 were compared, and Pearson product-moment correlation coefficients between them are shown in Fig. 11. Although the LP-area-S from MIO Fuse was smaller than the scores from Polar H7, because of the averaging effect of MIO Fuse, there was strong correlation between the LP-area-S of MIO Fuse and that of Polar H7. The correlation became weaker in the LP-area-S from a short recording duration, such as the case of LP-area-S from RRI data recorded every $5 \mathrm{~min}$ $(r=0.46)$. To validly grasp the comparative rise and fall of LP-area-S in the episodes, we require their durations to be longer than certain minutes. On the basis of the results in Fig. 11, we decided to use $15 \mathrm{~min}$ as a minimum unit of the duration of an episode.

\section{References}

1. Agelink MW, Boz C, Ullrich H, Andrich J (2002) Relationship between major depression and heart rate variability. Clinical consequences and implications for antidepressive treatment. Psychiatry Res 113:139-149

2. Akselrod S, Gordon D, Ubel FA, Shannon DC, Barger AC, Cohen RJ (1981) Power spectrum analysis of heart rate fluctuation: a quantitative probe of beat-to-beat cardiovascular control. Science 213(4504):220-222

3. Antelmi I, de Paula RS, Shinzato AR, Peres CA, Mansur AJ, Grupi CJ (2004) Influence of age, gender, body mass index, and functional capacity on heart rate variability in a cohort of subjects without heart disease. Am J Cardiol 93:381-385

4. Bigger JT, Kleiger RE, Fleiss JL, Rolnitzky LM, Steinman RC, Miller JP, The Multicenter Post-infraction Research Group (1988) Components of heart rate variability measured during healing of acute myocardial infraction. Am J Cardiol 61:208-215

5. Borell E, Langbein J, Despres G, Hansen S, Leterrier C, MarchantForde J, Marchant-Forde R, Minero M, Mohr E, Prunier A, Valance D, Veissier I (2007) Heart rate variability as a measure of autonomic regulation of cardiac activity for assessing stress and welfare in farm animals - a review. Physiol Behav 92:293-316

6. Chatters LM (1988) Subjective well-being evaluations among older Black Americans. Psychol Aging 3(2):184-190

7. Choi J, Ahmed B, Gutierrez-Osuna R (2012) Development and evaluation of an ambulatory stress monitor based on wearable sensors. IEEE Trans Inf Technol Biomed 16(2):279-286 
8. Cummins R (2010) Subjective wellbeing, homeostatically protected mood and depression: a synthesis. J Happiness Stud $11: 1-17$

9. Dasgupta P (2001) Human well-being and the natural environment. Oxford University Press, New York

10. Diener E (1984) Subjective well-being. Psychol Bull 95(3):542-575

11. Diener E, Tay L (2014) Review of the day reconstruction method (DRM). Soc Indic Res 116:255-267

12. Dolan P, Peasgood T, White M (2006) Review of research on the influences on personal well-being and application to policy making. Final report for Department for Environment Food \& Rural Affairs

13. Dolan P, Layard R, Metcalfe R (2011) Measuring subjective wellbeing for public policy: recommendations on measures. Center for economic performance, special paper no. 23

14. Durand M, Smith C (2013) The OECD better life initiative: how's life? And the measurement of well-being. Paper prepared for the IARIW session at the 2013 World Statistics Conference. OECD. Retrieved from http://www.iariw.org/papers/2013/Dur andPaper.pdf

15. Erjanti O, Rudenko S (2014) Bluetooth low energy (Smart) heart rate variability sensor demo app for Android (Open source codes of a mobile application software licensed by the MIT license). Retrieved from https://github.com/oerjanti/BLE-Heart-rate-varia bility-demo

16. Eurostat (2008) Harmonised European time use surveys 2008 guidelines. Eurostat methodologies and working papers. Retrieved from http://ec.europa.eu/eurostat/ramon/statmanuals/ files/KS-RA-08-014-EN.pdf

17. Evans J, Macrory I, Randall C (2015) Measuring national wellbeing: life in the UK, 2015. Office for National Statistics of the United Kingdom. Retrieved from http://webarchive.nationalarc hives.gov.uk/20160105160709/; http://www.ons.gov.uk/ons/ dcp171766_398059.pdf

18. Faruqee H, Muhleisen M (2003) Population aging in Japan: demographic shock and fiscal sustainability. Jpn World Econ 15:185-210

19. Hektner JM, Schmidt JA, Csikszentmihalyi M (2007) Experience sampling method: measuring the quality of everyday life. Sage Publication, California

20. Kahneman D, Krueger AB, Schkade DA, Schwarz N, Stone AA (2004) A survey method for characterizing daily life experiences: the day reconstruction method. Science 306(1776):1776-1780

21. Kahneman D, Krueger AB (2006) Developments in the measurement of subjective well-being. J Econ Perspect 20(1):3-24

22. Kemp AH, Quintana DS, Gray MA (2011) Is heart rate variability reduced in depression without cardiovascular disease? Biol Psychiatry 69(4):e3-e4

23. Lazarus RS, Folkman S (1984) Stress, appraisal, and coping. Springer, New York

24. Lazarus RS (1999) Stress and emotion: a new synthesis. Springer, New York

25. MacKerron G (2011) Happiness economics from 35000 feet. J Econ Surv 26(4):705-735

26. Ministry of Internal Affairs and Communication (2016) Jinko suikei (Flash report of the estimation of the population on July in 2016). Ministry of Internal Affairs and Communication of Japan. Retrieved from http://www.stat.go.jp/data/jinsui/pdf/201607.pdf

27. Muramatsu N, Akiyama H (2011) Japan: super-aging society preparing for the future. Gerontologist 51(4):425-432

28. Nahshoni E, Aravot D, Aizenberg D, Sigler M, Zalsman G, Strasberg B, Imbar S, Adler E, Weizman A (2004) Heart rate variability in patients with major depression. Psychosomatics 45:129-134
29. Parak J, Korhonen I (2014) Evaluation of wearable consumer heart rate monitors based on photoplethysmography. In: 36th Annual international conference of the IEEE engineering in medicine and biology society, pp 3670-3673

30. Perrez LA, Schoebi D, Wilhelm P (2000) How to assess social regulation of stress and emotions in daily family life? A computer-assisted family self-monitoring system (FASEM-C). Clin Psychol Psychother 7:326-339

31. Schiffrin HH, Nelson SK (2010) Stresses and happy? Investigating the relationship between happiness and perceived stress. J Happiness Stud 11:33-39

32. Schnell I, Potchter O, Epstein Y, Yaakov Y, Hermesh H, Brenner S, Tirosh E (2013) The effects of exposure to environmental factors on heart rate variability: an ecological perspective. Environ Pollut 183:7-13

33. Seigneur J-M (2011) The emotional economy for the augmented human. In: Proceedings of the 2nd augmented human international conference, $\mathrm{p} 24$. doi:10.1145/1959826.1959850

34. Selye H (1936) A syndrome produced by diverse nocuous agents. Nature 138:32

35. Selye $\mathrm{H}$ (1950) Stress and the general adaptation syndrome. $\mathrm{Br}$ Med J 1(4667):1383-1392

36. Selye H (1973) The evaluation of the stress concept. Am Sci 61(6):692-699

37. Sloan RP, Shapiro PA, Bagiella E, Boni SM, Pail M, Bigger JT, Steinman RC, Gorman JM (1994) Effect of mental stress throughout the day on cardiac autonomic control. Biol Psychol 37:89-99

38. Spierer DK, Rosen Z, Litman LL, Fujii K (2015) Validation of photoplethysmography as a method to detect heart rate during rest and exercise. J Med Eng Technol 39(5):264-271

39. Stein PK, Kleiger RE, Rottman JN (1997) Differing effects of age on heart rate variability in men and women. Am J Cardiol 80:302-305

40. Stiglitz JE, Sen A, Fitoussi JP (2010) Miss-measuring our lives: why GDP doesn't add up. The report by the Commission on the measurement of economic performance and social progress. The New Press, New York

41. Stucke D, Ruse MG, Lebelt D (2015) Measuring heart rate variability in horses to investigate the autonomic nervous system activity - pros and cons of different methods. Appl Anim Behav Sci 166:1-10

42. Suh E, Diener E, Fujita F (1996) Events and subjective wellbeing: only recent events matter: erratum. J Pers Soc Psychol 71(5):842

43. Tamura T, Maeda Y, Sekine M, Yoshida M (2014) Wearable photoplethysmographic sensors-past and present. Electronics 3:282-302

44. Task Force of the European Society of Cardiology the North American Society of Pacing Electrophysiology (1996) Heart rate variability: standards of measurement, physiological interpretation, and clinical use. Circulation 93:1043-1065

45. Trimmel M (2015) Relationship of heart rate variability (HRV) parameters including $\mathrm{pNNxx}$ with the subjective experience of stress, depression, well-being, and every-day trait moods (TRIMT): a pilot study. Ergon Open J 8:32-37

46. Umetani K, Singer DH, McCraty R, Atkinson M (1998) Twentyfour hour time domain heart rate variability and heart rate: relations to age and gender over nine decades. J Am Coll Cardiol 31(3):593-601

47. Uonuma city (2016) Shiteiku betsu jinko cho (Demographic survey on each village in Uonuma ciry). Uonuma city. Retrieved from http://www.city.uonuma.niigata.jp/docs/2015012900543/ file_contents/20160630jinnkoutoukei.pdf

48. Uonuma city (2015) Uonuma shi jinko vision (A population vision of Uonuma city). Uonuma city. Retrieved from http:// 
www.city.uonuma.niigata.jp/docs/2015103000077/file_contents/ 2.pdf

49. Valenti G (2013) Optical heart rate monitoring module validation study. In: Conference paper in 2013 IEEE international conference on consumer electronics, pp 195-196
50. Woo MA, Stevenson WG, Moser DK, Trelease RB, Harper RM (1992) Patterns of beat-to-beat heart rate variability in advanced heart failure. Am Heart J 123(3):704-771 